\title{
Higher Vocational Education Project Curriculum Practice
}

\author{
Tiejun Chen \\ Hebei Vocational\&Technical College of Building Materials, Qinhuangdao 066004, PR China \\ chen4490@126.com
}

Keywords: Higher vocational education, Project management,Curriculum reform, Virtual reality.

\begin{abstract}
Vocational training objectives of the teaching system is to train modern professional skilled personnel to adapt to the rapid development of modern technology. University teaching system should be compatible with the use of modern teaching methods to develop and produce closely related to teaching. Some of the existing curriculum should be appropriate reform breakthrough from the contents of choreography and teaching methods to adapt to the requirements of today's society for personnel training. The informatization project of teaching examples are introduced, in summing up the experience and to evaluate the effect of the at the same time to explore the feasibility and necessity of promotion, some existing problems are discussed.
\end{abstract}

\section{Introduction}

In June 2011, the Ministry of Education issued the "education information 10-year development plan (2011-2020) (draft)" pointed out that the level of informatization of education in China can not meet the development requirements of the modernization of education and the needs of the masses expectwith the international advanced level, there is still a significant gap, promote the education of information technology is still a long and arduous task. Proposed to the development goals for 2020: the formation of the education information system compatible with the development goals of national education modernization, the basic realization of the comprehensive coverage of all regions and types of schools at all levels of broadband networks, the basic completion everyone can enjoy high-quality educational resourcesinformation technology learning environment, and significantly improve the level of education management information, education information on the whole approach international advanced level, and support the leading role of education reform and development is fully apparent. For higher vocational education should vigorously promote vocational schools digital campus construction to raise the overall level of teaching, training, research, management, services, information technology applications. Information technology to promote personnel training mode of reform, to support high quality skilled personnel training, play consolidate the scale of IT in vocational education, improve the quality and unique service to the community in a supportive role[1].

I taught the "building engineering survey" is a production practices combining courses from 2008 onwards we will try to teaching reform, new teaching methods, modern teaching methods, knowledge points, and production practicesintegration of course content, flexible assessment methods and gradually replace the traditional teaching methods and course content system, give full play to our existing information technology, to optimize the teaching process, to improve the internship training, project teaching, case studies, vocational contest informationlevel. Innovative educational content using modern techniques, to promote the integration of information technology and curriculum, to enhance the students' use of self-learning ability of the Internet, cell phones, and other information channels. Use of enhanced reality, virtual simulation and other advanced techniques to strengthen practice teaching. 


\section{Curriculum design concept of innovation}

The "Construction engineering survey" course of construction works, professionals an important professional skills class for students mapping, knowledge map, according to the drawings loft, deformation monitoring, technical skills and ability[2]. Vocational building works related professional personnel training objectives, combined with the measurement of demand for new technology and the talent market, we follow during the course design:

In accordance with the requirements of practical engineering knowledge for construction engineering survey, finishing some of the typical tasks to design the construction surveying skills training system and the necessary theoretical knowledge of learning systems.

Service-oriented professional competence in the building construction job training, re-arranging the course content.

School-enterprise cooperation in curriculum development, and strive to achieve "skills training, knowledge, learning and development of quality integration" and "teaching, learning and doing" integration.

Focus on standards and enterprise demand for qualified personnel, concerned about the construction of measurement technology of new technologies, new applications, simulation enterprises working situation[3].

Teaching the use of modern means of information, to enable students to become the subject of study to improve the students use the Internet to find the analysis of the problem, problem-solving abilities.

Strengthen teachers literacy, the development of quality teaching resources, combined with the depth of information technology for teaching materials and practical techniques[4].

Based on the above six concepts, we developed a combination of a construction process, as a link to IT "skills training, knowledge learning and development of quality curriculum content system integration ". To break in accordance with the order of the textbook chapters to teach the curriculum system, teaching materials, a re-division, in accordance with the construction process is divided into five aspects: "Establishment of Horizontal Control","Elevation Control to Establish","Foundation Construction Survey","Measurement of the Main Monstruction" and "Settlement Observation", Involved in the whole process until the completion of the construction and acceptance from the approach of building construction. This teaching, learning and integration of the curriculum system allows students in learning the course content at the same time, the entire construction process with understanding and pave the way for other follow-up courses to learn[5].

Scientific and rational design of a teaching reform key to the success, the author of the research group early in the curriculum was once tried several other curriculum ideas, but after several years of practice effects are less than ideal, researchThe reason is that:

a) The previous curriculum reform has always been the teaching materials are mainly line course design ideas to turn around the textbook. Today's curriculum bold use form of the textbook changes, discarded the outdated method of operation in accordance with the application of knowledge of the construction on the use of knowledge to break up the textbook teaching materials re-combination, add the latest technology from the engineering practice, to encourage students to acquire knowledge through the Internet.

b) The previous curriculum developed in the course design, teaching group of teachers to develop programs, which would lead to a lot of knowledge can not and engineering closely integrated, teaching content to seem boring and many students lose learning interest. Today's curriculum, we employ experienced depth of engineering and technical personnel involved in the fresh engineering examples and teaching knowledge points in close connection with the project of curriculum scenario-based teaching, has a high interest in learning so that students learn and can learn a result, learning will be useful.

c) The previous teaching in the arrangement of training content focused primarily on the operation of the instrument itself, using the instrument in engineering involves very little. Today's 
curriculum training content in close connection with the project, to develop a series of simulation engineering training programs, students not only learn the operation of the instrument also know how to use knowledge to solve problems in practical engineering[6].

d) The previous assessment focuses on students' mastery of theoretical knowledge, practical applications of assessment is less. Now we have the usual assessment of the project training students as an important part of the end of the examination paper is also a change of the previous theoretical content and replaced by engineering situations, assessment of students with the knowledge to solve practical problems, reflecting the higher vocational education training objectives.

Current curriculum program after three semesters of teaching practice and achieved gratifying results, greatly enhance the students' enthusiasm for learning, learning on the Internet use increasing emphasis on the ability to significantly strengthen the knowledge to solve practical problems,recognized curriculum initiatives. Innovative curriculum ideas laid the foundation for the success of curriculum reform.

\section{Teaching content arrangement project}

Causes and teaching materials to use in the curriculum with little success is directly related to the traditional mode of teaching basic teaching materials to the main line to arrange the teaching content. Lesson plans to write a textbook chapter as a unit, too much reliance on textbooks, so that makes teaching the layout of a lack of vitality and new ideas[7]. Students lectures for teaching content to a lack of looking forward to psychological, a look at textbooks to know what the content of teacher talk, flowing style of teaching presented many students lose interest in learning, reducing the psychological desire to acquire new knowledge, which also have been affected by the learning atmosphere of the classroom. The students' learning enthusiasm is not high, the learning initiative of arranging teaching contents decreased with certain relation exists between. But if the move toward the other extreme, a powerful and unconstrained style type arrangement of the teaching content and the students get confused, much less.

Reasonable arrangements for teaching content is essential for the effectiveness of the curriculum reform, curriculum guiding ideology to limit the first two years of curriculum practice in the use of teaching materials, we never make a major adjustment. The past two years we went to the construction site field surveys, in-depth engineering and technical personnel, drawing on the relevant experience of other universities, we carried out a bold reform the use of textbooks. Under the premise of the actual project as the carrier, consistent with the actual job tasks to establish horizontal control, vertical control to establish the basis of construction survey, the main construction survey, settlement observation of the construction process-based teaching, teaching materialsthe the dismantling combination of re-rounding outdated operating practices to add new operating means, so that the knowledge point of the project, practical[8].

Project of curriculum reform and training of professional quality and the actual ability to cultivate the sense of innovation, to play the advantages of this curriculum must be done:

According to the construction process to implement a series of training, so that students get" system of skills training"," system of knowledge" and" full quality development training".

Ensure that project tasks and project real close to the actual construction as the carrier, a real engineering tasks, technical documentation, standards and norms as a teaching and learning materials, and measurement solutions to the real construction project as a case, combined with the schools existing teaching resources to set eacha project task, to determine their training requirements and implementation of programs.

Building construction site simulation, the learning context of classroom learning context focuses on the "show the construction scenario, the analysis of technical issues, the preparation of measurement"; training workplace learning context focuses on "operational training". This training has two forms: First, from the training teachers operation demonstrates the students to observe; training teachers guide students to learn by doing, to complete the assigned project tasks. 
Construction work training sites training program consistent with the real production, also can not affect the content of the production process simulation.

\section{Conclusion}

Higher vocational education curriculum reform to change the teaching methods and teaching methods, the content of education reform is the key to reform. Higher vocational education to train high-level professional skills of personnel, with some theoretical knowledge of the theoretical knowledge in the teaching process, learning and professional skills development is as important as learning to ignore the theoretical knowledge to focus only on practical skills training into the medium vocational education level, learning to ignore the practical skills training focuses on theoretical knowledge is lost the characteristics of higher vocational education follows the general higher education training model.

Scientific and reasonable arrangements for lectures to train high-level skilled personnel, curriculum policy-makers to carefully consider the problem, using advanced teaching methods to improve teaching effectiveness is limited by teaching their own ability to use IT Evaluation System, a wide range oftest the wisdom of the decision makers of the curriculum.

A successful curriculum reform is not only the change of students' learning content, learning state and also changes in the new teaching concept of cognition and to the use of information technology.

\section{References}

[1] Ministry of education of the people's Republic of China,Education informatization ten year development plan(2011-2020)( The draft),September 2011.

[2] Zhihai Chou, Keep abreast of professional project of poineering education reform, Chemical occupation technology education, vol. 03,2011.

[3] Ke Song, Xiaolin Guo, Yuqi Wang. The education technology in teaching and training in the application of [ J]. Journal of Changchun University,2009, (04).

[4] Jie Mou, Shilun Wang. Web teaching webpage visual traction of [ $\mathrm{J}$ ]. Automation instrumentation,2010, (01).

[5] Ying Li. Based on Cooperative Learning Model in electronic commerce professional bilingual teaching reform research $[\mathrm{J}]$. Electronic commerce,2012, (01).

[6] Jinbao Zhang, Song Li, Peng Chen. The connotation of online courses and the core elements [J ]. Modern distance education research,2010, (01).

[7] Jinqi Li. Based on the perspective of educational concept under the new situation of China's education reform of public security [J ]. Public security education,2011,(07).

[8] Jing Ding, The informatization of education management evaluation standard system, Journal of Educational Development, vol. 04,2011. 